\title{
LA INTERCULTURALIDAD EN EL APRENDIZAJE MUSICAL DEL NIVEL INICIAL A TRAVÉS DEL GÉNERO SANJUANITO
}

\section{LA INTERCULTURALIDAD EN EL APRENDIZAJE MUSICAL DEL NIVEL INICIAL A TRAVÉS DEL GÉNERO SANJUANITO}

MÓNICA DEL CARMEN BRAVO VELÁSQUEZ MSC ${ }^{1}$

MERCY JULIETA LOGRONO PHD²

Recibido: 18 de junio de 2018 Aceptado: 22 de octubre de 2018

\footnotetext{
${ }_{1}^{1}$ Pontificia Universidad Católica del Ecuador, Facultad de Ciencias de la Educación, Quito, Ecuador, mbravo002@puce.edu.ec

${ }^{2}$ Universidad Central del Ecuador, Quito, Ecuador mercyjulieta@yahoo.com.mx
} 
ill|lin 


\section{LA INTERCULTURALIDAD EN EL APRENDIZAJE MUSICAL DEL NIVEL INICIAL A TRAVÉS DEL GÉNERO SANJUANITO}

\section{LA INTERCULTURALIDAD EN EL APRENDIZAJE MUSICAL DEL NIVEL INICIAL A TRAVÉS DEL GÉNERO SANJUANITO}

Mónica del Carmen Bravo Velásquez, Mercy Julieta Logrono

Palabras clave: interculturalidad, aprendizaje, infancia; música, destrezas; sanjuanito.

Key words: interculturality; learning; childhood; music; skills; sanjuanito.

\section{RESUMEN}

El artículo que se presenta se inscribe en el marco de la realización del proyecto de iniciación musical realizado en la Carrera de Educación Inicial de la Universidad Central del Ecuador, durante los años 2014-2017, cuyo propósito fundamental fue diseñar una metodología para iniciar a los niños y niñas de manera creativa y lúdica en la música. Esta fue aplicada y validada en el Centro Infantil
Laura Barahona de la ciudad de Quito, con infantes de 4 a 5 años de edad. La investigación, por su naturaleza, es cualitativa y por su modalidad de aplicación es cuasi experimental. Los hallazgos de su aplicación en uno de los géneros abordados desde el proyecto demuestran que el uso de ritmos musicales de carácter intercultural, como el sanjuanito, género muy arraigado en la herencia cultural an- 
dina, facilitan el aprendizaje del ritmo. En la infancia, la actividad musical se inicia a partir del ritmo y gracias a la interacción de los géneros tradicionales con los niños y las niñas existe una mejor conexión con el aprendizaje. El vínculo cultural y afectivo con una memoria musical afincada genera condiciones pedagógicas idóneas para un mejor desarrollo de las destrezas y habilidades musicales, de incidencia directa en los ámbitos cognitivo, psicomotriz y afectivo.

\section{ABSTRACT}

This article is part of the musical initiation project that was carried out for the Early Education Major at the Universidad Central del Ecuador between 2014 and 2017. Its fundamental purpose was to design a methodology to introduce children to music in a creative and playful way. This methodology was validated and applied in the Laura Barahona Children's Center of Quito with children between 4 and 5 years of age. This research is qualitative by its nature, and due to its modality of application, it is quasi-experimental. The findings of this project's application with one of the genres studied demonstrate that the use of intercultural music rhythms such as the sanjuanito - which is deeply rooted in Andean cultural heritage - facilitate an early learning of rhythm. This project also demonstrates that childrens' interaction with traditional genres encourages a better connection with learning related to the cultural and affective link and a fixed musical memory, and generates ideal pedagogic conditions for a better development of musical skills and abilities, which have direct impact on cognitive, affective and psychomotor areas.

\section{INTRODUCCIÓN}

El presente artículo tiene como objetivo principal demostrar cómo el uso de elementos interculturales presentes en la música y el baile tradicionales favorecen al desarrollo de destrezas cognitivas, psicomotrices y afectivas, ligadas al aprendizaje de la música como medio de expresión y lenguaje, de niños y niñas de cuatro años. 
El currículo de Educación Inicial ${ }^{1}$ propone como perfil de salida del nivel, niños y niñas que:

i) Se reconozcan como personas independientes con características particulares y pertenecientes a una familia y una comunidad; ii) Identifiquen sus principales características y preferencias, que les permitan reconocerse como seres únicos e irrepetibles, contribuyendo al proceso de la construcción de su identidad y generando niveles crecientes de confianza y seguridad en sí mismos; iii) Interactúen con empatía y solidaridad con los otros, con su entorno natural y social, practicando normas para la convivencia armónica y respetando la diversidad cultural; iv) Reconozcan y apliquen nociones temporo-espaciales y lógico-matemáticas para solucionar retos cotidianos acordes a su edad; v) Expresen, con un lenguaje comprensible, pensamientos, sentimientos, emociones, acciones y eventos utilizando su lengua materna y el lenguaje propio de su cultura y entorno; vi) Disfruten de las diferentes manifestaciones artísticas como medios de expresión de sus emociones, plasmando sus ideas y aprendizajes; vii) Demuestren habilidad motriz gruesa y fina en la ejecución coordinada de movimientos y desplazamientos que permiten facilitar la estructuración de su imagen corporal. (2014)

Para el logro de este perfil, el currículo contempla tres ejes fundamentales de desarrollo con sus respectivos ámbitos de estudio. En el subnivel dos (objeto de estudio de la investigación) se propone:

Eje de Desarrollo personal y social, con el ámbito identidad y autonomía.

Eje de Descubrimiento natural y cultural, con los ámbitos relacionados con el medio natural y cultural y las relaciones lógico-matemáticas.

Eje de Expresión y comunicación, con los ámbitos de comprensión y expresión del lenguaje, expresión artística y expresión corporal y motriz.

La música, como disciplina, estaría enmarcada dentro del ámbito de expresión artística. Sin embargo, de acuerdo a sus posibilidades de acción, puede llegar a tener incidencia en el perfeccionamiento de todas las demás áreas, ya que favorece el desarrollo de las funciones básicas del aprendizaje como: atención, memoria, comprensión, lenguaje activo, sensopercepciones, esquema corporal, lateralidad, direccionalidad, nociones temporales, motricidad fina, motricidad gruesa, nudo categorial

\footnotetext{
${ }^{1}$ Currículo Educación Inicial 2014. República del Ecuador
} 
o armonización (movimiento y dominio del espacio).

Los primeros años de vida del ser humano son determinantes porque en esta etapa se sientan las principales bases del desarrollo cerebral, emocional y psicomotriz, es decir, el desarrollo de todo lo será la vida presente y futura del individuo. Los cinco primeros años son cruciales porque en ellos se realizan importantes procesos neurofisiológicos que configuran las conexiones y funciones cerebrales. La música, tanto la que se escucha como la que se ejecuta, es uno de los principales medios para propiciar el desarrollo pleno de niños y niñas, ya que integra procesos que comprometen la simultaneidad hemisférica y una mayor cantidad de interconexiones neuronales. La presencia de la música desde edades tempranas es de vital importancia para la adquisición de destrezas específicamente musicales y también para lograr una evolución integral del individuo (Sarget, 2003). De esta forma, mientras más pronto se exponga a niños y niñas a la educación musical, existen mayores probabilidades de potenciar y desarrollar buenas condiciones en los distintos ámbitos de su formación.

La capacidad para percibir la música está relacionada con la necesidad del oído humano de aprender su lengua materna para poder comunicarse. Reynoso (2010) afirma que hasta los recién nacidos reaccionan a estímulos musicales: por ejemplo, al mes de nacidos los bebés pueden discriminar tonos de diferentes frecuencias; a los seis meses se habla ya de una 'musicalidad' desarrollada; y a los tres o cuatro años, niños y niñas comienzan a reproducir la música de la cultura en la que están inmersos. Esta capacidad precoz de percibir y reproducir la sonoridad cercana, permite establecer un vínculo afectivo que nace del sentido de pertenencia, es decir, ser parte de una familia, de un colectivo o una comunidad. La capacidad de expresión también aumenta a través de la familiarización con el lenguaje musical característico de su medio, el cual se incorpora de manera natural, a distintas acciones de su vida cotidiana y con significados de la propia cultura.

En el plano de las destrezas cognitivas, niños y niñas deben desarrollar procesos físicos y psicológicos. Por medio de la práctica musical se desarrollan diferentes habilidades como la audición, la relación espacial, la motricidad fina, la coordinación visomotora, la lateralidad, la memoria mecánica, la evocación auditiva, el ritmo, la concentración y la expresión de emociones entre otros (Reynoso, 2010). En el plano cognitivo se considerarán cinco niveles referentes a procesos mentales identificables: recuerdo, comprensión, análisis, síntesis y aplicación. Al tocar una pieza musical, por ejemplo, se 
ponen en juego todos estos componentes, lo cual quiere decir que al exponer a niños y niñas a prácticas instrumentales se está favoreciendo el desarrollo de destrezas cognitivas. (Quevedo, 2018).

Si la música es utilizada como parte de un proceso general de enseñanza-aprendizaje holístico, aprovechando su estructura conformada por elementos sonoros analíticos como son: el ritmo, la melodía, la armonía, el timbre, la altura, la intensidad y la duración, los cuales se hallan integrados en el fenómeno musical, lo deducible es que la práctica de sus elementos específicos o en conjunto estimulen los elementos constitutivos de la inteligencia (atención, memoria, percepción, lógica, concentración, coordinación, observación, inhibición, direccionalidad, relajación) y los elementos del pensamiento (ideas simples, nociones, conceptos) que son estimuladores también del aprendizaje de un instrumento o disciplina práctica de la música. (Alvarado, 2012, p. 45).

En relación al desarrollo psicomotor, la influencia de los estudios realizados por Piaget es esencial para la comprensión del desarrollo psicológico del niño, donde se afirma que la evolución de la inteligencia acontece a partir de la expe- riencia motriz. La acción, el movimiento y la experiencia con el propio cuerpo sobre el mundo de los objetos, permiten acceder, más tarde, al pensamiento operatorio y a la representación. El descubrimiento del propio cuerpo y sus sensaciones, la exploración de las posibilidades de movimiento y funciones corporales, constituirán experiencias necesarias sobre las que se construirá el pensamiento infantil.

La actividad psicomotriz implica una relación directa de la capacidad motriz y psíquica. El cuerpo vivido es un concepto de base sensorial y afectiva, y puede ser tratado musicalmente. El conocimiento del propio cuerpo se relaciona, en primer lugar, con el conocimiento del esquema corporal, su orientación y lateralidad, además de la percepción espacial y temporal, y la consiguiente estructuración espacio temporal. "Música y movimiento están fuertemente enlazadas, ya que se basan en relaciones espacio-temporales, de ahí que se favorece el desarrollo de destrezas musicales a través del movimiento; a la vez la música, por su condición rítmica genera posibilidades de desarrollar destrezas psicomotoras". (Quevedo, 2018, p. 54)

A nivel afectivo, la música favorece la comunicación de niños y niñas con sus pares y con todos aquellos que conviven en su entorno. Por otra parte, la música se constituye en el me- 
dio más idóneo de expresión de sentimientos y emociones que, bajo el cobijo de la canción, pueden ser canalizados de una manera espontánea y no invasiva. Uno de los aspectos más importantes de la acción musical es, sin duda, la posibilidad de socialización y desarrollo de la capacidad creativa. Jugar con el sonido a través de las canciones e interactuar con los demás en danzas, rondas y juegos crea hábitos musicales que acompañan importantes espacios de su vida, sumados al placer que produce el hacer música. La importancia del arte como medio potenciador de la dimensión social del individuo fue ya observado por Vygotsky, quien en su teoría observa la "necesidad de ampliar la experiencia del niño si queremos crear bases suficientemente sólidas para su actividad creadora" (2003, p. 23).

El proceso de globalización devenido de las políticas socioeconómicas ha provocado una mayor migración y movilidad humana a nivel regional y mundial, suscitando una serie de cambios que han afectado las dinámicas sociales internas, las cuales han regresado la mirada a las minorías y a las diversidades. Es necesario buscar mediaciones de convivencia social y cultural, replantear el enfoque y rol de la educación en la construcción del ciudadano. La escuela aparece actualmente como uno de los espacios principales para aprender a vivir juntos, e implica según la UNESCO el respeto al pluralismo, la comprensión del otro, el participar y cooperar con los demás y la convivencia en paz (Salido, 2008, p. 270). Touriñan (2006) sugiere que la interculturalidad posibilita estructurar esa convivencia, al aceptar la diversidad cultural como un elemento positivo para conocer, respetar y valorar al otro y mirarse desde lo plural.

La música ha sido y es un medio de expresión presente en todas las culturas a lo largo del tiempo y el espacio. Mediel (2008) plantea que la música es un elemento muy potente para trabajar con la diversidad en el aula, y se basa en la idea de que esta es una necesidad universal de expresión y comunicación. No existe pueblo que no cante, baile o toque instrumentos, ni persona que no haya sido atravesada por una experiencia musical. Salido (2008) refuerza esta concepción cuando cita a Siankope (2004) quien plantea que "las posibilidades que ofrece la música como medio para vivir la interculturalidad son espléndidas, ya que esta es un vehículo de comunicación profundo [...] y los recursos que ofrece no solo son fuente de disfrute, diversión y aprendizaje sino también una baza muy interesante en pro de la interculturalidad" (Salido, 2008, p. 275). 


\section{Interculturalidad, música y educación}

Según la Ley Orgánica de Educación Intercultural el nivel de educación inicial es "el proceso de acompañamiento al desarrollo integral que considera los aspectos cognitivo, afectivo, psicomotriz, social de identidad, autonomía y pertenencia a la comunidad y región de los niños y niñas desde los tres años hasta los cinco años de edad, garantiza y respeta sus derechos, diversidad cultural y lingüística, ritmo propio de crecimiento y aprendizaje, y potencia sus capacidades, habilidades y destrezas" (LOEI, 2017, Art. 40).

La interculturalidad refiere a la interacción que se da entre dos o más culturas en las numerosas manifestaciones de la vida social, en un nivel de horizontalidad y comunicación dialógica. Fleuri (2002), citado por Rosa Oliveira (2015), menciona que el interculturalismo propone el desenvolvimiento de procesos de intercambio entre los sujetos y entre las diferentes culturas. Al pensar en educación intercultural dos son los principales aspectos que la caracterizan a partir del prefijo inter, el cual conduce a la noción de reciprocidad e intercambio, donde la relación intercultural indica: (i) una situación en que personas de culturas diferentes interactúan, o (ii) una actividad que requiere de intercambio (Oliveira, 2015).
En el ámbito educativo, la música ofrece extensos canales para vivir la interculturalidad desde ámbitos amplios y, a la vez, profundos, ya que permite, como medio de expresión, un involucramiento del ser humano desde la emocionalidad. El arte y la música tienen la propiedad de generar espacios de diálogo y vivencia con diversidad de culturas y articular diferentes manifestaciones como la poesía, los juegos tradicionales o las danzas. Para Samper (2010) "la música es también un tipo de narrativa en cuanto es la expresión de un relato construido desde biografías y subjetividades de individuos o grupos particulares que expresan a través de su discurso musical emociones, ideas, conceptos y preguntas" (p. 301).

Para abordar la interculturalidad es necesario también acercarse a la idea de diversidad, cuya significación hace referencia a variedad, multiplicidad y pluralidad. La Declaración Universal de la UNESCO determina a la Diversidad Cultural como patrimonio común de la humanidad. El manifiesto declara que:

La cultura adquiere formas diversas a través del tiempo y del espacio. Esta diversidad se manifiesta en la originalidad y la pluralidad de las identidades que caracterizan a los grupos y las sociedades que componen la humanidad. Fuente de intercambios, de innovación y de creatividad, la diver- 
sidad cultural es tan necesaria para el género humano como la diversidad biológica para los organismos vivos. En este sentido, constituye el patrimonio común de la humanidad y debe ser reconocida y consolidada en beneficio de las generaciones presentes y futuras. (Art. 1, 2001)

El trabajo intercultural permite crear un espacio de acercamiento mutuo y de entendimiento, en el que todos participan o deberían participar en igualdad de condiciones. En la Educación Intercultural se menciona la importancia de lo diverso, del intercambio con "el otro", de la necesidad de conocer la diferencia para respetarla. En este contexto es fundamental pensar, de acuerdo a Bernabé Villodre (2013), en actitudes no discriminatorias como punto de partida del reconocimiento de la diversidad y la inclusión. Es necesario pensar en prácticas en las que se adecúen los distintos aspectos que posibiliten el hecho educativo, con miras a proporcionar una educación para todos y todas.

Ibarretxe (2014) considera que, en una visión amplia del concepto de diversidad, se debe contemplar el trabajo con valores como tolerancia y aceptación del otro, sensibilidad y empatía hacia los más desfavorecidos, haciendo hincapié en las labores de adaptación curricular y compensación, lo que supone una educación personalizada e inclusiva a la vez. La inclusión educativa considera a todos y cada uno de los niños y niñas, evitando la exclusión de aquellos que se encuentran en situaciones de desventaja ya sea por motivos de discapacidad física o intelectual, diferencias de género o pertenencia a grupos culturales o étnicos marginados.

Para hablar de interculturalidad es sustancial comprender al otro y la cultura de la que forma parte. La música, como elemento de cohesión social, es una de las herramientas más adecuadas para llegar a este entendimiento intercultural porque es la manifestación con mayor presencia en todos los ámbitos de la vida de un pueblo. Basta recordar los cantos de siembra y cosecha que acompañan el trabajo agrícola, o los tonos funerarios que amparan el retorno de las almas, la música para danzar en las festividades o los arrullos de cuna. No se puede concebir una celebración o rito social sin su presencia. Podría decirse, entonces, que la música es la experiencia artística más significativa del ser humano. 


\section{PROCESO METODOLÓGICO}

La investigación que se llevó a cabo es aplicativa y de carácter cuasi experimental, ya que se trata de analizar de qué manera el sanjuanito, ritmo propio de la serranía ecuatoriana, ayuda a desarrollar las destrezas cognitivas, afectivas y psicomotoras de los niños y niñas.

En el proceso metodológico, se aplicaron diversas técnicas de investigación que se articularon entre sí. Para evaluar el perfil musical de los niños y niñas junto con el desarrollo de destrezas, primero se utilizó una evaluación diagnóstica y, posteriormente, para estudiar los cambios suscitados por la intervención del proyecto, se volvió a aplicar la misma herramienta, a fin de evaluar los logros alcanzados. Para registrar la información de manera diaria, se utilizaron fichas individuales para cada niño y niña, en donde se asentaron los avances al final de cada encuentro. Durante todo el proceso se realizó una observación directa y complementaria a través de fichas de cotejo y se llevó un diario de campo en donde se señalaron los avances más importantes y significativos.

Previa a la autorización de las autoridades de educación y de los progenitores, se plantearon treinta encuentros realizados en un plazo de 5 meses en los que se trabajaron distintos tipos de vivencias musicales con visión intercultu- ral. En estos encuentros participaron 26 infantes de cuatro a cinco años de edad, pertenecientes al paralelo B, sub-nivel 2, del Centro Infantil Laura Barahona, ubicado al norte de la ciudad de Quito.

A este plantel acuden niños y niñas de barrios urbanos marginales del Norte de Quito. El grupo fue seleccionado por las autoridades de la institución, sin que haya mediado criterio alguno en esta decisión. En el proceso intervinieron una investigadora y dos músicos/as expertos/as, y un profesor de la entidad, a modo de acompañante.

\section{A. Diagnóstico}

Se inició el proyecto con una evaluación diagnóstica que permitió tener una visión general del nivel de desarrollo rítmico, melódico y auditivo del grupo de niños y niñas. Se determinaron casos particulares de mayor o menor habilidad respecto a la media. Al mismo tiempo, se observó el nivel de desarrollo del lenguaje hablado y cantado, capacidad de atención y comprensión, conciencia de lateralidad y participación en el grupo.

La ficha de diagnóstico se estructuró como una doble entrada en la cual, por un lado, se hizo un listado de todos los estudiantes participantes y, por otro, se señalaron diez parámetros a observar. Los niveles de ejecución se determina- 
ron aplicando la escala de Likert con los criterios: (D) Destacadamente; (S) Satisfactoriamente; (M) Medianamente; y (E) Escasamente.

Los parámetros que se evaluaron en los niños y niñas a través de la lista de cotejo incorporan los siguientes indicadores:

(1) Entona afinadamente; (2) Percute con precisión rítmica; (3) Discrimina y reconoce sonidos adecuadamente; (4) Se desplaza a diferentes velocidades y

controla su cuerpo en los silencios; (5) Manifiesta memoria musical; (6) Comprende las consignas y responde adecuadamente a ellas; (7) Relaciona imagen y sonido; (8) Tiene conciencia de la lateralidad; (9) Trabaja en grupo participativamente con respeto y agrado; y (10) Pronuncia adecuadamente el lenguaje hablado y cantado.

\section{Resultados del diagnóstico}

\section{Tabla 1.}

\section{Diagnóstico de entrada sobre desarrollo de destrezas musicales.}

\begin{tabular}{|l|l|c|c|c|c|c|c|c|}
\hline Ítem & Parámetros evaluados de entrada y salida & D & S & S & M & M & E & E \\
\hline 1 & Entona afinadamente & & & & 2 & $8 \%$ & 24 & $92 \%$ \\
\hline 2 & Percute con precisión rítmica & & & & 4 & $15 \%$ & 22 & $85 \%$ \\
\hline 3 & Discrimina y reconoce sonidos adecuadamente & & & & 16 & $62 \%$ & 10 & $38 \%$ \\
\hline 4 & $\begin{array}{l}\text { Se desplaza a diferentes velocidades y controla su } \\
\text { cuerpo en los silencios }\end{array}$ & & & & 18 & $31 \%$ & 8 & $69 \%$ \\
\hline 5 & Manifiesta memoria musical & & 8 & $31 \%$ & 12 & $46 \%$ & 6 & $23 \%$ \\
\hline 6 & $\begin{array}{l}\text { Comprende las consignas y responde adecuada- } \\
\text { mente a ellas }\end{array}$ & & 8 & $31 \%$ & 10 & $38 \%$ & 8 & $30 \%$ \\
\hline 7 & Relaciona imagen y sonido & & & & 2 & $8 \%$ & 24 & $92 \%$ \\
\hline 8 & Tiene conciencia de la lateralidad & & 3 & $12 \%$ & 10 & $38 \%$ & 13 & $50 \%$ \\
\hline 9 & $\begin{array}{l}\text { Trabaja en grupo participativamente con respeto } \\
\text { yagrado }\end{array}$ & & & & 16 & $73 \%$ & 6 & $27 \%$ \\
\hline 10 & $\begin{array}{l}\text { Pronuncia adecuadamente el lenguaje hablado } \\
\text { y cantado }\end{array}$ & & & 6 & $23 \%$ & 20 & $77 \%$ \\
\hline
\end{tabular}

Elaboración autoras. Aplicación Centro Infantil Laura Barahona. Año 2017. 
Los resultados más destacables del diagnóstico determinaron que la mayor parte de los niños y niñas participantes tenían un escaso y/o mediano desarrollo de las habilidades evaluadas. Se pudo observar que los ámbitos en los que hubo menor índice de desarrollo fueron aquellos relacionado con habilidades de entonación, pues el 92\% de niños y niñas no lograron dicha destreza, aspecto que implica un bajo desarrollo auditivo. Igualmente, un 92\% de niños y niñas no estableció ninguna relación entre imagen y sonido, y mostraron problemas en la identificación del mundo sonoro.

Se evidencia también un escaso desarrollo de la percusión rítmica del $85 \%$ de niños y niñas.

Otro de los problemas encontrados está relacionado con la pronunciación del lenguaje hablado y cantado, desarrollado por un 77\% de los niños y niñas.

Mientras que la discriminación de sonidos es desarrollada medianamente por el 62\% de los niños, un 38\% de niños tiene un escaso nivel de avance.

Los niveles de lateralidad fueron escasamente alcanzados por el 50\% de niños y niñas, y fueron medianamente logrados por el $38 \%$ de niños y niñas; y solo un 12\% logró un desarrollo satisfactorio.
Además, hubo un 31\% de niños que mostraron una satisfactoria memoria musical, pues lograron cantar nanas infantiles y asociar a las personas que las cantaron; un 46\% lo hicieron de modo aceptable pero para el 23\% de niños y niñas fue difícil recordar las canciones aprendidas en su entorno musical.

En lo relativo a las destrezas con un mayor índice de desarrollo, encontramos el siguiente diagnóstico:

Se establece que el 31\% de niños y niñas comprende consignas y responde de manera satisfactoria; un 38\% lo hace medianamente y sólo un 30\% lo hace escasamente. De la misma manera, mostraron un mejor desarrollo en el trabajo de grupo en donde el $73 \%$ de niños y niñas participa con agrado; y sólo un 27\% de ellos no se motiva a participar y se separan para realizar actividades fuera del grupo que no tienen relación con las actividades que se desarrollan en el aula. En otras ocasiones, cuando lo hacen, dificultan la actividad y, por momentos, captan la atención de sus pares que lo secundan.

En la siguiente figura se puede observar los resultados de los parámetros evaluados. 
Figura 1. Evaluación Diagnóstica Inicial. Centro Infantil Laura Barahona.

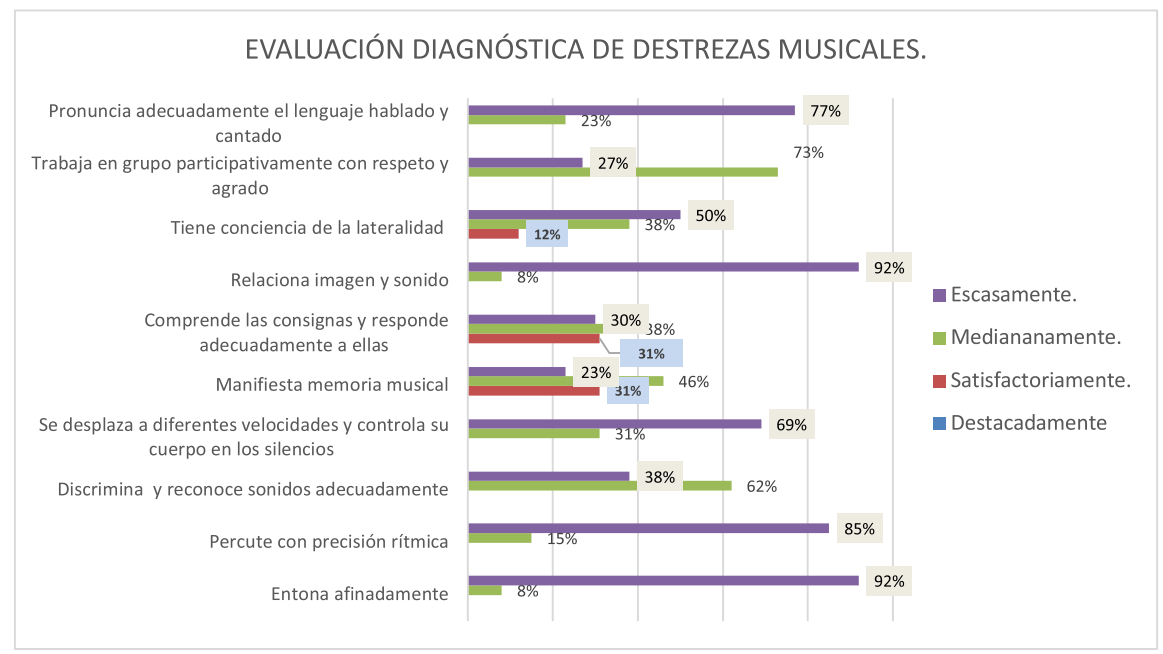

Elaboración Autoras.

\section{B. Proceso}

Para la investigación se realizó una planificación basada en los treinta encuentros. Durante el transcurso del estudio se efectuaron los ajustes pertinentes de acuerdo a las observaciones registradas en el diagnóstico inicial y anecdotarios que cada uno de los investigadores llevó a lo largo de cada jornada. Además de los apuntes escritos, una de las investigadoras registró las clases a través de grabaciones en video.

En el primer encuentro se realizó una clase en la que se trabajaron los aspectos a observar, se expusieron juegos rítmicos de desplazamiento y percusión; se enseñó una canción sencilla con tres sonidos, se leyó una secuencia de sonidos con imágenes y se realizó un baile grupal. Se propusieron las actividades de trabajo con los niños mientras dos investigadores, conjuntamente con la docente de aula, Ilenaron las fichas de diagnóstico. A cada niño y niña se le colocó previamente en el pecho una tarjeta con su nombre, para facilitar su identificación.

Las actividades que se diseñaron tuvieron como objetivo el desarrollar musicales de incidencia directa en el avance de destrezas cognitivas, psicomotrices y afectivas a través de la música 
con un enfoque intercultural. Se planteó evidenciar el desarrollo de estas destrezas por medio de la ejecución de acciones enmarcadas en los diez parámetros establecidos.

Cada encuentro o clase tuvo una duración de una hora y se estableció una estructura estable y secuencial, las partes que se determinaron fueron:

- Ubicación espacial y lateralidad

- Desplazamientos rítmicos y percusión corporal

- Audición y canto

- Ejecución instrumental y prelectura

- Baile colectivo

Las actividades musicales que se efectuaron en las clases estuvieron basadas fundamentalmente en el canto, la ejecución de instrumentos de percusión básica, la percusión corporal y los desplazamientos rítmicos, los bailes folclóricos, la lectura rítmica y melódica, la discriminación auditiva de parámetros musicales y la audición de obras del folclore nacional.

\section{Género musical escogido y materiales}

La investigación tomó como punto de referencia fundamental el género sanjuanito por ser el de mayor dispersión a lo largo de la serranía ecuatoriana, por lo tanto el más cercano a la memoria musical de niños y niñas del centro educativo seleccionado para el estudio, la mayoría de los cuales son descendientes de migrantes del campo andino.

El sanjuanito es un baile y música indígena y mestiza del Ecuador de construcción binaria. Godoy (2007) lo define como "danza con texto, estructurado en tonalidad menor" (p. 181). El compositor Luis Humberto Salgado, citado por Mullo (2009) lo conceptúa como "una danza de forma binaria, en compás de 2/4 y movimiento allegro moderato. Tiene una introducción o interludio que divide sus dos partes (A-B). Se ejecuta con ritornellos" (p. 52). Este género musical, al decir del historiador musical Pablo Guerrero (2005), tiene un posible origen prehispánico y mucha semejanza con el huayno peruano. Godoy (2007) por su parte considera que "su origen como danza ceremonial indígena posiblemente está en la antigua celebración del Inti Raymi, evento que los españoles lo sustituyeron por la fiesta del 24 de junio en homenaje a San Juan" (p. 181). El nombre de sanjuanito, al decir del musicólogo Segundo Luis Moreno, citado por Guerrero (2005) derivó del hecho de que se bailara durante los días del festejo de San Juan. Salgado, además, establece la división entre sanjuanito de blancos y de indios. El primero, de corte mestizo, es cantado y bailado durante todo el año, mientras que el de carácter indígena es 
una danza específica de las fiestas de San Juan. (Mullo, 2009). Godoy (2007) puntualiza que el sanjuanito indígena tiene una construcción melódica en base a la escala pentáfona anhemitónica (sin semitonos), mientras que el mestizo es diatónico y puede llegar a contemplar cromatismos. Sin embargo, al ser música viva, el sanjuanito se ha ido acoplando y reescribiendo de acuerdo a las necesidades del contexto. "El sanjuanito, al igual que otros géneros musicales mestizos, es el producto de un largo proceso de innovación, variación, invención, préstamo cultural, eliminación selectiva, aceptación social; fusión y síntesis de elementos musicales, sociales y culturales." (Godoy, 2007, p. 182)

Al ser un género familiar en la vida cotidiana de las comunidades resulta óptimo para inciar con él un proceso de educación musical. Pedagógicamente se busca trabajar motivando la zona de desarrollo próxima. (Vygotsky, 1931) comprendida como la distancia entre el nivel de desarrollo efectivo de las personas o lo que es capaz de realizar por sí sólo un niño o niña, y lo que podrá realizar de manera potencial con la ayuda de un proceso metodológico cercano a su realidad cultural.

Se partió de la danza como medio primario de relación con el género ya que al ser un ritmo característico de las fiestas populares este permitió una rápi- da conexión con niños y niñas, de una manera festiva y lúdica.

A continuación se buscó determinar por oído el acompañamiento de base, este ostinato rítmico es tocado por el bombo y se mantiene sonando durante toda la pieza:

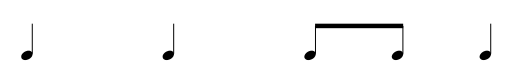

Para afianzar el ritmo del género se buscó una relación con el lenguaje, de tal manera que fuera más fácil de recordar y de mantener a lo largo de la ejecución:

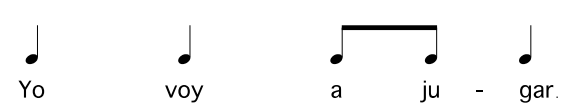

Al mismo tiempo, se trabajó el esquema rítmico con desplazamientos y con la percusión corporal en distintos planos del cuerpo, además de instrumentos de percusión básica.

En los siguientes encuentros se fueron implementando otras secuencias rítmicas y se fue estableciendo su relación con una frase significativa para niños y niñas:
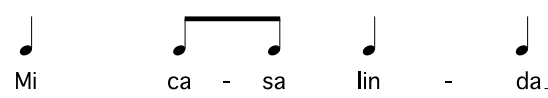


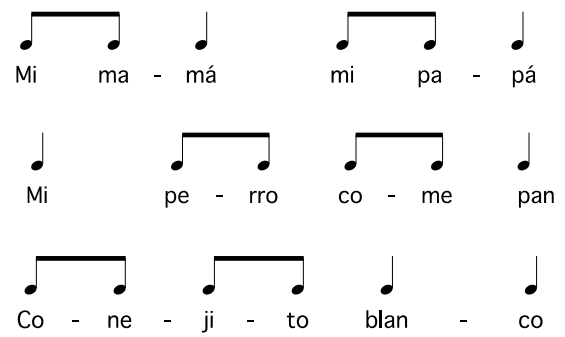

Para la codificación y decodificación de estas estructuras rítmicas se buscó trabajar con material concreto, de tal manera que niños y niñas pudieran interactuar y comprender la representación de las secuencias rítmicas. Se construyeron fichas de madera pintadas de colores. El color verde para determinar los valores largos (negra) y amarillas para valores cortos (corcheas), a cada niño y niña se le entregaron tres fichas verdes y dos amarillas para que lea y escriba los distintos ritmos.
Figura 2. Fichas de lectura rítmica
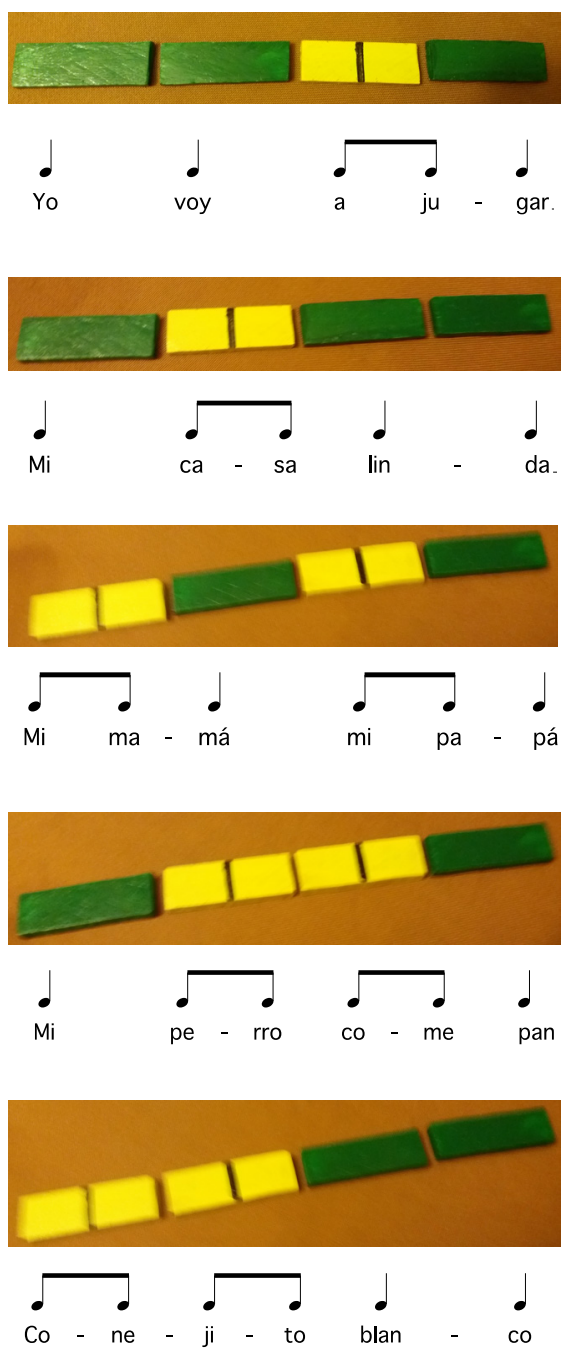

Elaboración autoras 
Estos esquemas rítmicos fueron la base del acompañamiento para el montaje de otras piezas musicales y se interpretaron con instrumentos de la banda rítmica. En cada clase, la base del sanjuanito fue llevada por uno o dos niños, quienes lo ejecutaban con el bombo, mientras el resto de niños lo cantaban y bailaban. Siempre se contó con el acompañamiento armónico de la guitarra y la ejecución melódica a través de la flauta dulce, instrumentos interpretados por los músicos-investigadores.

En el aspecto melódico se tomaron como base dos sanjuanitos tradicionales: El curiquingue y Tío Yuma, el primero proveniente de la provincia de Cotopaxi y el segundo de Imbabura. Ambas piezas están construidas sobre escalas pentáfonas: el Curiquingue escala pentáfona menor y Tío Yuma escala pentáfona mayor.
Las melodías pentafónicas son características del folclore indígena y están presentes en todas las culturas, no solo de la serranía, sino inclusive en la zona de Esmeraldas en donde se encuentran asentamientos de cultura afrodescendiente. La dispersión de este sistema de pensamiento ha posibilitado una mayor cercanía con este tipo de lenguaje melódico, por esta razón es que utilizar estas canciones para dar comienzo a un proceso de iniciación musical generó su rápida captación y un desarrollo melódico más acelerado.

A continuación, se presenta la partitura de la pieza El curiquingue. Al principio, niños y niñas la bailaron simulando los movimientos que se sugieren en la canción, para luego terminar cantándola y ejecutando su rítmica con los instrumentos de percusión básica. 


\section{Fl curiquingue}

Sanjuanito
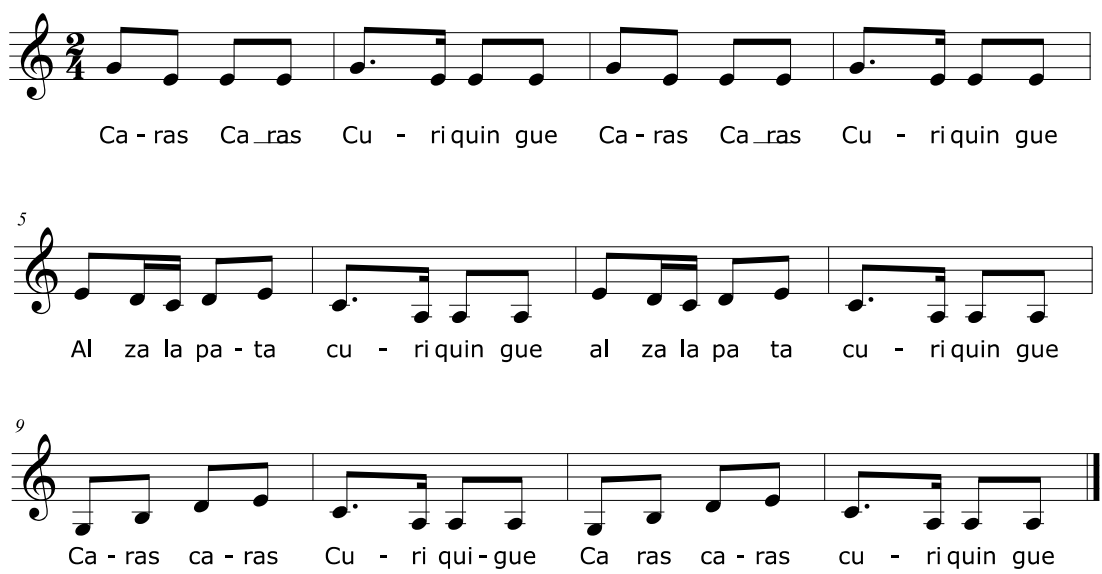

Caras caras

Curiquingue (bis)

alza la pata

Curiquingue (bis)
Caras caras

Curiquingue (bis)

alza la mano

Curiquingue (bis)

Caras Caras

Curiquingue

Caras caras

Curiquingue (bis)

da la media vuela

Curiquingue (bis)
Caras caras

Curiquingue (bis)

da la vuelta entera

Curiquingue (bis)

\section{Caras Caras \\ Curiquingue}

El curiquingue es un canto tradicional que remite a los movimientos del ave curiquingue, pájaro venerado por los indígenas por ser augurio de buena suerte. El baile se realiza con danzantes disfrazados de esta ave ritual, los cuales bailan guiados por el texto de la canción. La melodía empieza con el intervalo de $3 \mathrm{~m}$ descendente el cual, es sabido, facilita la entonación por estar 
en el ámbito adecuado para las voces infantiles y por ser el punto de partida de varios métodos de iniciación musical. En la investigación se planteó el trabajo como pregunta-respuesta en la cual los niños cantaron las frases comprendidas entre el ámbito de tercera y la docente-investigadora la respuesta que comprende un descenso a la sexta inferior.

En paralelo, se crearon o compilaron en total diez canciones de corte pentatónico y pentafónico, para reforzar la entonación de la memoria musical de melodías con estas escalas.

Finalmente, el proyecto contó con una banda rítmica de instrumentos elaborados de bambú realizados a la medida. Se trabajó con bombos y tambores pequeños, marimbas trifónicas, panderos, claves, cajas chinas, cascabeles de semillas y flautas de pan trifónicas. Se comprobó que estas últimas no son de fácil ejecución para niños y niñas de esta edad, por lo tanto, fueron descartadas en el proceso.

\section{RESULTADOS}

Como se había mencionado a lo largo de la investigación, en cada encuentro se llevaron listas de observación que permitieron evidenciar los avances en cada uno de los aspectos que se marcaron como determinantes para la evaluación del proyecto.

En las dos últimas sesiones, se realizó una evaluación personalizada, en la que se pudo contar con datos certeros sobre los avances individuales. Se tomaron en cuenta cuatro aspectos fundamentales: a) nivel de desarrollo melódico en cuanto a la reproducción afinada de canciones y estructuras melódicas pentafónicas, lo cual permitió evaluar los parámetros relacionados con entonación, discriminación auditi- va y memoria musical; b) precisión rítmica en la ejecución y discriminación de esquemas rítmicos, lo cual esta íntimamente relacionado con: percusión con precisión rítmica, desplazamiento a diferentes velocidades, discrimanción y reconocimiento de sonidos largos y cortos; c) memoria musical, relacionada con la reproducción exacta de canciones aprendidas, pronunciación adecuada del lenguaje hablado y cantado, percusión con precisión rítmica; d) lecto-escritura de esquemas rítmicos a través del sistema de fichas de lenguaje analógico, relacionado con discriminación y reconocimiento adecuado de sonidos, relación imagen-sonido,comprensión de consignas. 
Al término de la investigación se realizó, además, una actividad que dio cuenta de los avances a nivel del contexto grupal y evidenció el progreso de la participación individual para el logro de objetivos colectivos. Se realizó un miniconcierto al interior de la institución, en el cual se interpretaron cuatro canciones con acompañamiento instrumental. Se dividió la clase en cinco grupos. Cada uno de ellos intepretó alguno de los esquemas rítmicos aprendidos con uno de los instrumentos del conjunto. Además, se montó la pieza El curiquingue con los pasos y vestuario tradicional, lo cual puso en el ambiente de fiesta el aprendizaje musical.

A continuación se muestra el cuadro de resultados al término de la investigación:

Tabla 2. Resultados del desarrollo de destrezas musicales

\begin{tabular}{|l|c|c|c|c|c|c|c|c|}
\hline \multicolumn{1}{|c|}{ Parámetros evaluados de salida } & D & $\begin{array}{c}\text { Destaca- } \\
\text { damente }\end{array}$ & S & $\begin{array}{c}\text { Satis- } \\
\text { factoria- } \\
\text { mente }\end{array}$ & M & $\begin{array}{c}\text { Media- } \\
\text { namente }\end{array}$ & E & $\begin{array}{c}\text { Escasa- } \\
\text { mente }\end{array}$ \\
\hline Entona afinadamente & 6 & $23 \%$ & 8 & $31 \%$ & 12 & $46 \%$ & & \\
\hline Percute con precisión rítmica & 8 & $31 \%$ & 13 & $50 \%$ & 4 & $15 \%$ & 1 & $4 \%$ \\
\hline $\begin{array}{l}\text { Discrimina y reconoce sonidos } \\
\text { adecuadamente }\end{array}$ & 5 & $19 \%$ & 12 & $46 \%$ & 7 & $27 \%$ & 2 & $8 \%$ \\
\hline $\begin{array}{l}\text { Se desplaza a diferentes velocidades } \\
\text { y controla su cuerpo en los silencios }\end{array}$ & 10 & $38 \%$ & 12 & $46 \%$ & 4 & $15 \%$ & & \\
\hline Manifiesta memoria musical & 8 & $31 \%$ & 10 & $38 \%$ & 6 & $23 \%$ & 2 & $8 \%$ \\
\hline $\begin{array}{l}\text { Comprende las consignas y respon- } \\
\text { de adecuadamente a ellas }\end{array}$ & 10 & $38 \%$ & 12 & $46 \%$ & 6 & $23 \%$ & 2 & \\
\hline Relaciona imagen y sonido & 8 & $31 \%$ & 14 & $54 \%$ & 3 & $12 \%$ & 1 & $4 \%$ \\
\hline Tiene conciencia de la lateralidad & 12 & $46 \%$ & 8 & $31 \%$ & 4 & & 2 & \\
\hline $\begin{array}{l}\text { Trabaja en grupo participativamen- } \\
\text { te con respeto y agrado }\end{array}$ & 8 & $31 \%$ & 12 & $46 \%$ & 5 & $19 \%$ & 1 & $4 \%$ \\
\hline $\begin{array}{l}\text { Pronuncia adecuadamente el len- } \\
\text { guaje hablado y cantado }\end{array}$ & 10 & $38 \%$ & 12 & $46 \%$ & 4 & $15 \%$ & & \\
\hline
\end{tabular}


Figura 3. Desarrollo de destrezas musicales. Elaboración autoras.

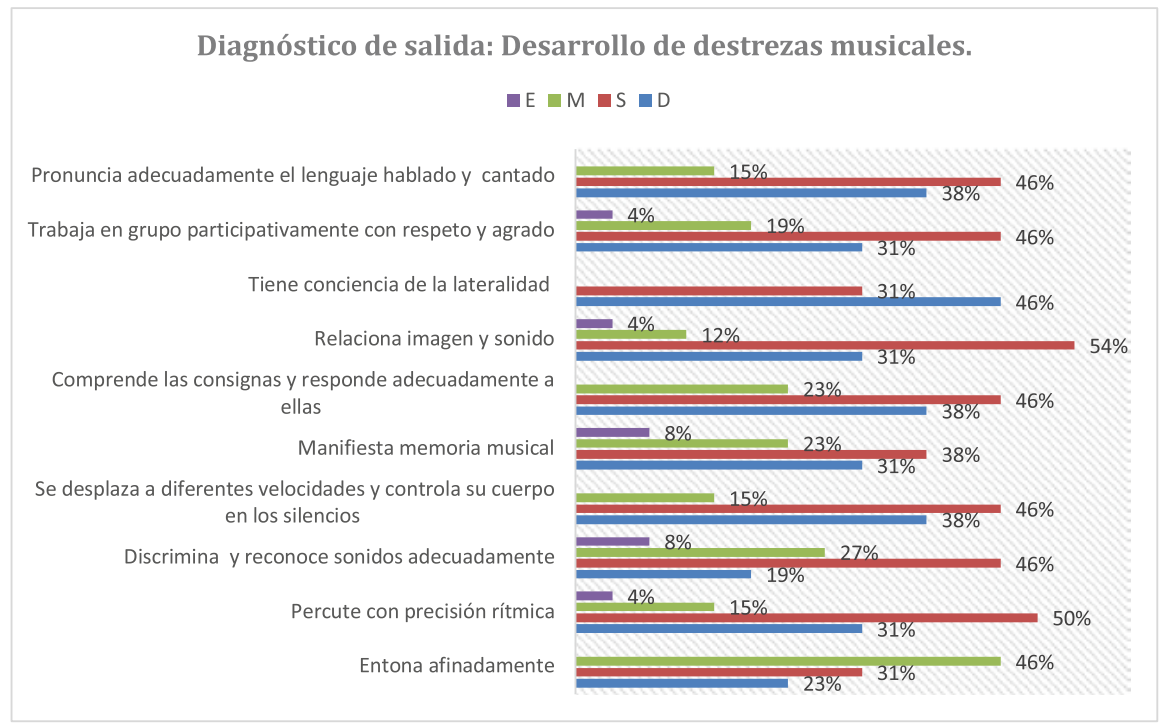

Como se evidencia en la tabla, así como en la figura N 2., hay un cambio notablemente favorable en el desarrollo de la mayoría de destrezas relacionadas con la iniciación musical, mostrándose un cambio estadístico significativo, pues claramente se desplazan los valores ubicados en el criterio "escasamente" que se muestran en la tabla 1 a los criterios "destacadamente", y "satisfactoriamente". Así, mientras que muy pocos niños no lograron avanzar en el desarrollo de destrezas (Tabla 2 y figura 3), sí se apreciaron cambios fundamentales en lo relacionado con su desarrollo rítmico-melódico. En ellos, se destacan sobremanera la percusión con precisión rítmica y la relación imagensonido por el uso de las fichas de material concreto. Las dos destrezas son las que más se desarrollan en relación con el diagnóstico de entrada.

Se nota, además, cómo en la totalidad de los parámetros establecidos la mayoría de niños y niñas tuvieron un desempeño satisfactorio y, en varios casos, aumentó el número de casos destacables. Hay que tomar en cuenta que, en el caso del desarrollo del lenguaje y la entonación melódica, ningún niño o niña tuvo un escaso desempeño, y que se mejoró considerablemente el desarrollo de la lateralidad, lo cual da cuenta del avance en estos aspectos. 


\section{DISCUSIÓN DE RESULTADOS}

A través de la puesta en marcha del proyecto de iniciación musical con enfoque intercultural, como apoyo al aprendizaje musical de infantes de cuatro años, se demostró cómo el interactuar con elementos presentes en las culturas tradicionales facilita el acercamiento al hecho educativo, favoreciendo no solo el aprendizaje musical sino el desarrollo de destrezas cognitivas, psicomotrices y sociafectivas. La música en las culturas tradicionales ecuatorianas tiene un papel protagónico como manifestación cultural y como elemento de cohesión social. A través de ella se canta, se baila, se conmemora y se expresan diversidad de sentimientos humanos. Por otra parte, esta demanda para su ejecución de precisión y concentración, de desarrollo de la memoria y la puesta en marcha de una simultaneidad de acciones relacionadas con la ejecución instrumental. Riaño (2013) considera que "las manifestaciones musicales, artísticas y rituales son, y han sido siempre, señas vivas de la identidad cultural de las sociedades" (p. 67). Dadas estas características de la música, se considera un medio idóneo para generar una serie de aprendizajes relacionados con otros ámbitos del saber humano.

La constitución de la República reconoce al Ecuador como un "Estado constitucional de derechos y justicia social, democrático, soberano, independiente, unitario, intercultural, plurinacional y laico" (Constitución del Ecuador 2008). En este sentido se justifica ampliamente una investigación sustentada en la interculturalidad ya que permite fortalecer desde la infancia rasgos fundamentales para la construcción sostenibles de la identidad ecuatoriana

Almeida (2007) reconoce a la interculturalidad como un tipo de relación establecida entre culturas que propugnan un diálogo y un encuentro entre ellas, a partir del reconocimiento mutuo de sus respectivos valores y formas de vida.

Al ser el Ecuador un país multiétnico y pluricultural es propicio encontrar maneras de interacción entre culturas y promover el trabajo con la otredad. Es necesario generar mecanismos que posibiliten, desde la educación, propiciar espacios de reflexión y cuestionamiento sobre el yo y los otros. Samper (2011) manifiesta que "en un contexto pluricultural, estos interrogantes se enuncian frente a los procesos de significación del aprendizaje, construcción de identidad, autonomía crítica y pertinencia" (p. 302). El autor resalta la empresa de que otros saberes, tradicionalmente excluidos por 
la academia, ingresen a los currículos y a las prácticas pedagógicas.

Pérez (2013), a su vez, observa que "en la actualidad la globalización implica una multiculturalidad cada vez más acentuada, lo que ha provocado que el desarrollo de la competencia intercultural se considere un tema de gran importancia para investigadores y educadores" (p. 288). La educación intercultural hace referencia, al decir del autor a un tratamiento de la diversidad cultural desde procesos educativos holísticos en constante modulación.

De la misma manera, el proyecto DUM DUM desarrollado por Pérez (2012), en el contexto de la educación española, propone un programa de inclusión social a través del trabajo cooperativo desarrollado por medio de la creación de un proyecto musical. Este se enmarca dentro del contexto español, en el cual, dado a los procesos de migración, cada vez están más presentes diversidad de culturas en el aula. Pérez parte de la idea desarrollada por Mary Ruth MacGinn acerca de la ópera de New York con el proyecto LOVA (La ópera, un vehículo de aprendizaje). Su método utiliza un círculo de percusión mediante el cual se expone a niños y niñas a la diversidad de ritmos de las diferentes culturas españolas y de los migrantes; en DUM DUM también se interactúa con instrumentos de percusión básica y la metodología apunta a la improvisación musical.

Bernabé Villodre (2012) usa la canción como medio fundamental de interculturalidad, la investigadora manifiesta que "la canción popular se utiliza como nexo entre los pueblos dado a la riqueza etnomusicológica enriquecida por siglos de contacto entre civilizaciones" (p. 239) Riaño (2013), citando a Furnó y Malbrán (2000), manifiesta que existe "una fascinación de los niños por la escucha y re-escucha de una misma canción" (p. 71). Es importante conocer el uso, el valor y la adecuación de la literatura musical en el aula para estudiar los procesos de transmisión y salvaguarda del patrimonio artístico y musical en nuestras sociedades.

En el caso de la investigación presentada por Bernabé Villodre (2012), se trabaja con diversidad de canciones provenientes de diversas culturas europeas y africanas. En el caso de la investigación que presentamos, la canción se remite fundamentalmente a un género musical: el sanjuanito, por considerarlo uno de los más representativos de la cultura andina ecuatoriana. En España existe una mayor tradición de interactuación intercultural, tanto en el pasado como en el presente, por lo cual es válido trabajar con una mayor diversidad de géneros musicales. 


\section{CONCLUSIONES Y PERSPECTIVAS}

De los resultados mostrados, del análisis y discusión, se exponen a continuación las siguientes conclusiones:

- Una mayor movilidad humana pone nuevos retos tanto a los estados como a la educación. El concepto de identidad debe ser revisado en función de la diversidad y las propuestas educativas tienen que plantear necesariamente la inclusión, en términos de equidad social y cultural.

- Tener como sustento a la interculturalidad proporciona la base para la inclusión y el punto de vista diverso dentro del aula de clases.

- Contextualizar el aprendizaje con el hecho cultural enriquece el aprendizaje musical con la vivencia que proporciona la danza, los personajes, el juego, la dramatización y el uso de disfraces que permiten traer la fiesta al aula, dando mayor sentido de pertenencia al repertorio que se canta o ejecuta.

- La música como elemento fundamental de transmisión de valores culturales "vivos" es el medio idóneo para trabajar con la interculturalidad, en ella están presentes la canción, la danza, la ejecución de instrumentos y el ritual, el cual es el elemento contextualizador más importante.

A través de actividades musicales ligadas al canto, el movimiento, la ejecución de instrumentos y la audición niños y niñas del nivel inicial, desarrollan destrezas cognitivas relacionadas con la atención, comprensión, memoria, concentración y discriminación del mundo sensorial. Se desarrollan, además, habilidades psicomotrices gracias a la relación entre movimiento y ritmo. La sensibilidad y emocionalidad se ven acrecentadas, dado el efecto que tiene la audición musical y el canto melódico en el desarrollo de la memoria afectiva.

- La utilización de un género musical tradicional, en este caso el sanjuanito, como punto de partida para la iniciación musical facilita el aprendizaje rítmico, desde la ejecución del ostinado de base escrito en compás binario y el aprendizaje melódico por la familiaridad con el sistema modal pentáfono.

El carácter dinámico y estructural del sanjuanito, como género bina- 
rio, facilitan la interacción musical y social. Su ritmo constante y marcado permite ser "seguido" con naturalidad, ya que se relaciona con el nivel primario de regularidad fisiológica e instintiva.

- Relacionar estructuras rítmicas con frases significativas para los y las niñas promueve una rápida inserción en el ritmo musical, dado a la temprana adquisición del lenguaje materno niños y niñas tienen interiorizados un repertorio amplio de palabras y sus sonoridades que ayudan a discriminar las mismas sonoridades enmarcadas en esquemas rítmicos.

- El uso de material concreto, como las fichas de madera pintadas de colores, posibilitan una mejor comprensión de la relación sonido-duración y una más fácil manipulación para la codificación y decodificación de valores largos y cortos. Se demostró que no es necesario el llegar a abordar los códigos del lenguaje musical para que se den procesos de discriminación auditiva y lectoescritura rítmica.

- Contar con instrumentos construidos expresamente para la manipulación infantil y con materiales propios de la zona genera mayor acercamiento y disfrute de la práctica grupal y facilita la ejecución instrumental dadas las condiciones idóneas del material didáctico.

En próximas investigaciones se propone el trabajo con la música afro ecuatoriana que, si bien no tiene tanta incidencia en el contexto musical nacional, es una manifestación importante de la cultura negra ecuatoriana. Igualmente se podría tomar en cuenta a las culturas de la Amazonía, con las cuales el nivel de contacto es mínimo pero que representan igualmente una importante base de la pluriculturalidad del país. 


\section{REFERENCIAS BIBLIOGRÁFICAS}

[1]Almeida, Ñ. (2007). El fundamento constitucional de la pluriculturalidad en el Ecuador. Incidencias en su sistema jurídico. Tesis doctoral inédita. Universidad del Azuay. Disponible en: http://dspace.uazuay.edu.ec/bitstream/ datos/737/1/06379.pdf Fecha de consulta: 15 May.2018

[2] Alvarado, J. (2012) Estimulación de las inteligencias múltiples a través de los elementos de la música y el sonido. Cuenca: Universidad de Cuenca

[3] Bernabé Villodre, M. (2011). Cómo organizar el proceso de enseñanza musical de forma intercultural: propuesta para trabajar interculturalmente en el área de primaria. Dedica: Revista de Educaçáo e humanidades,2 março [p.217-234] ISSN 2182-018X Disponible en: http://revistaseug.ugr.es/index. php/dedica/article/view/7131 Fecha de acceso: 8 jun.2018

[3] (2012). Contextos pluriculturales, educación musical y educación intercultural. Revista El artista Nro 9. [en línea] Diciembre 2012 [p.235-248] $<$ http://www.redalyc.org/articulo.oa?id=87424873012> ISSN Fecha de acceso: 8 jun.2018
[4] (2013). Propuestas formativa intercultural el docente musical. Revista Educatio Siglo XXI, Vol 31, N. 22013 [p.297322] ISSN 1989-466X. Disponible en: <http://revistas.um.es/educatio/article/view/187641>. Fecha de acceso: 7 jun. 2018

[5] Reynoso, K. (2010). La educación musical y su impacto en el desarrollo. Revista de Educación y Desarrollo.

[5] Godoy, M (2007) Breve historia de la música del Ecuador. Biblioteca General de Cultura. Quito: Corporación Editorial Nacional.

[6] Guerrero, P (2005) Enciclopedia de la Música Ecuatoriana. Tomo II. Quito: CONMUSICA

[7] Ibarretxe, G. (Giraldez, A editora) (2014), Música complemento de formación disciplinar. Barcelona: Graó

[8] Mediel, O (2008) La canción como recurso de Educación Intercultural en la escuela: Cancionero Intercultural. Música. Arte. Diálogo. Civilización María Angustias Ortiz (coordinadora) Universidad de Granada. ISBN 978-989-952575-7 [p. 27-64] Disponible en: https://hum742.ugr.es/media/grupos/HUM742/cms/MUSICA.\%20 ARTE.\%20DIALOGO.\%20CIVILI- 
ZACION.pdf Fecha de acceso: 09 jun.2018

[9] Mullo, J (2009) Música patrimonial del Ecuador. Serie Cartografía de la memoria. Quito: Fondo Editorial Ministerio de Cultura

[10] Pérez, S. (2013). El desarrollo de la competencia intercultural a través de la educación musical: una revisión de la literatura. Revista Complutense de Educación. Vol 24. Nro 2. 2013 [p.287-301] SSN-e 1988-2793 Disponible en: https://revistas.ucm.es/index. php/RCED/article/view/42080 Fecha de acceso 30 May 2018

[11] Pérez, S, (2012). Dum Dum. Un programa diseñado para los problemas de inclusión a través del ritmo música. Dedica: Revista de Educaçáo e humanidades,2 março [p.217-234] ISSN2182018X Disponible en: http://revistaseug.ugr.es/index.php/dedica/ article/view/7130 Fecha de acceso 30 May 2018

[12] Quevedo, J. (2018) La música en el Desarrollo Integral de los niños y niñas en Método de Iniciación Musical Integral, Holístico e Intercultural. MIMUSI. Bravo, M, Logroño J. y Quevedo J. Quito: Ed. Universitaria.

[13] Reynoso, K. (2010). La educación musical y su impacto en el desarrollo.
Revista de Educación y Desarrollo N. 12. Enero-marzo 2010 [p.53-60] Disponible en: http://www.cucs. udg.mx/revistas/edu_desarrollo/ anteriores/12/012_Reynoso.pdf Fecha de acceso: 18 abr.2018

[14] Riaño, M. (2013). La importancia del patrimonio musical en el aula. Estudio sobre la opinión del profesorado en educación infantil. Revista Eufonía. Nro 58 Julio 2013 [p 68-78] URI: http://hdl.handle. net/10234/166582 Fecha de acceso: 21 May 2018

[15] Rosa Oliveira, A. da., \& Chequini Manzello (2015). Apontamentos críticos para uma educaçåo intercultural. Revista Iberoamericana de Educación. Vol 68 \#2. UFPal, Brasil [p.9-30] Recuperado a partir de https://rieoei.org/RIE/article/ view/182 Fecha de acceso: 19 abr.2018

[16] Rusinek, G.(2003). El aprendizaje musical como desarrollo de procesos cognitivos. Tavira: Revista de Ciencias de la Educación, 19, [49-62]. ISSN 0214-137X Fecha de acceso: 18 abr.2018

[17]Salido, Ma (2008) Mi musica, tú musica. Música. Arte. Diálogo. Civilización María Angustias Ortiz (coordinadora) Universidad de Granada. ISBN 978-989-95257-57 [p. 269-290] Disponible en: ht- 
tps://hum742.ugr.es/media/grupos/HUM742/cms/MUSICA.\%20 ARTE.\%20DIALOGO.\%20CIVILIZACION.pdf Fecha de acceso: 09 jun.2018

[18] Samper, A (2011) Educación musical a nivel superior e interculturalidad en el siglo XXI: nuevas epistemologías, nuevas aproximaciones didácticas. Revista El Artista N. 8 Diciembre [p.297- 316] Disponible en: http://www.redalyc. org/articulo.oa?id=87420931020 Fecha de acceso: 26 may. 2018
[19] Sarget,M.( 2003 ). La música en la educación infantil: Estrategias cognitivo-musicales. Revista de la Facultad de Educación de Albacete Nro 18 [p.197-209] ISSN 0214-4824 Disponible en: https://dialnet.unirioja.es/servlet/ articulo?codigo=1032322 Fecha de consulta: 22 abr. 2018

[20]Vygotsky, L. (2003) Imaginación y creación en la edad infantil.Buenos Aires: Populibros. Nuestra América. 